The following two persons have been newly appointed as the members of the Editorial Board of Analytical Sciences. The biographies of the current members are included in the June issues of the journal. Drs. Shukuro Igarashi and Tsutomu Masujima have retired from the Editorial Board.

\title{
ANALYTICAL SCIENCES EDITORIAL BOARD MEMBERS - BIOGRAPHIES
}

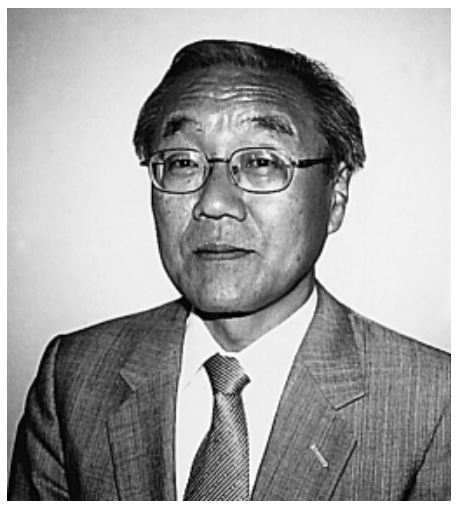

Associate Editor

Takashi MaEKawa, Professor of Inorganic Analytical Chemistry at the Faculty of Engineering, Ehime University, was born in 1943 in Hakodate, Hokkaido. He received a B. of Science (1966) and a D. of Science (1973) from Hokkaido University. He served as a Research Associate (1966 - 1980), Lecturer (1980 - 1987) and Associate Professor (1987 1990) in the Department of Chemistry, Faculty of Science, Hokkaido University. In 1990 he was appointed as a Professor of Applied Chemistry at Ehime University, Matsuyama, Ehime Prefecture. He was a research fellow of the Alexander von Humboldt Foundation (1978 1980) at the Institute of Physical Chemistry, Munich University. His current interest is the spectroscopic investigation of oxide glasses and the thermodynamics of high-temperature melts. Solid state NMR and voltammetry of glass melts up to $1800 \mathrm{~K}$ are included. His hobby is gardening and his daily work begins with greetings and water supply to lovely flowers.

Takehiko YAJIMA, Professor of Analytical Chemistry at the Faculty of Pharmaceutical Sciences, Toho University, was born in 1942 in Kure City, Hiroshima. He received BS (1966) and MS (1968) in Pharmaceutical Sciences from the University of Tokyo and a Ph.D (1974) in Microbiology from Georgetown University, USA. As a research microbiologist, he worked on antibiotics for several years at Tanabe Pharmaceutical Company, Japan. In 1978 he was appointed Associate Professor of Clinical Chemistry at Toho University, where he was promoted to Professor of Analytical Chemistry in 1982 and elected Dean of the Faculty of Pharmaceutical Sciences in 2000. His current research interests are focused on the biochemistry and analytical chemistry of interactions between intrinsic biological molecules and external substances, specifically, the mechanism of the transferrin-mediated transport of metals, such as $\mathrm{Al}$ and $\mathrm{Zn}$, protein-small molecule interactions and denaturation of proteins. These studies are carried out using HPLC, ICP-MS, ESI-MS, CE, etc. Professor Yajima has a passion for dogs and is most interested in the psychology of dogs next to analytical chemistry.

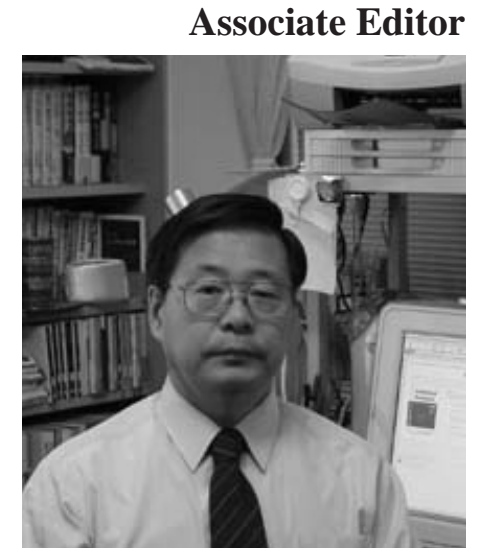

